
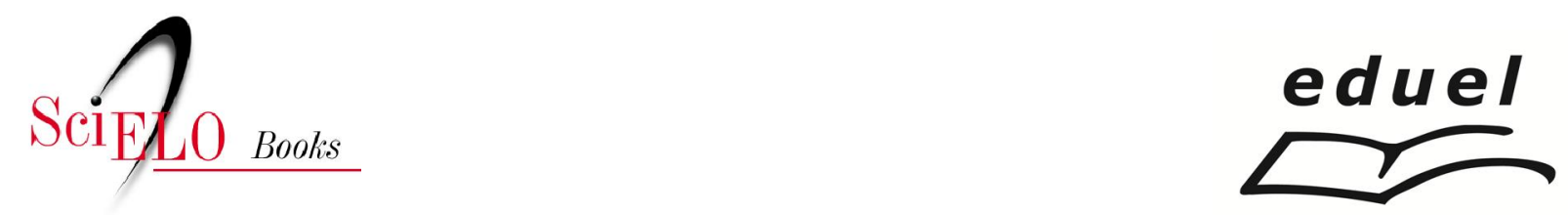

\title{
Rotina para toxoplasmose adquirida na gestação
}

\author{
Regina Mitsuka-Breganó \\ Fabiana Maria Ruiz Lopes-Mori \\ Italmar Teodorico Navarro \\ (orgs.)
}

\section{SciELO Books / SciELO Livros / SciELO Libros}

MITSUKA-BREGANÓ, R., LOPES-MORI, FMR., and NAVARRO, IT., orgs. Toxoplasmose adquirida na gestação e congênita: vigilância em saúde, diagnóstico, tratamento e condutas [online]. Londrina: EDUEL, 2010. Rotina para toxoplasmose adquirida na gestação. pp. 31-38. ISBN 978-857216-676-8. Available from SciELO Books $<\underline{\text { http://books.scielo.org }>\text {. }}$

\section{(1) $(0)$}

All the contents of this work, except where otherwise noted, is licensed under a Creative Commons Attribution-Non Commercial-ShareAlike 3.0 Unported.

Todo o conteúdo deste trabalho, exceto quando houver ressalva, é publicado sob a licença Creative Commons Atribuição Uso Não Comercial - Partilha nos Mesmos Termos 3.0 Não adaptada.

Todo el contenido de esta obra, excepto donde se indique lo contrario, está bajo licencia de la licencia Creative Commons Reconocimento-NoComercial-CompartirIgual 3.0 Unported. 


\section{Rotina para toxoplasmose adquirida na gestação}

\section{Triagem Sorológica}

Realizar exame sorológico na primeira consulta de pré-natal para pesquisa de anticorpos IgG (por métodos de IFI, ELISA, quimioluminescência, MEIA ou ELFA) e anticorpos IgM (por métodos de ELISA-captura de IgM, quimioluminescência, MEIA ou ELFA). Todas as gestantes devem participar dessa triagem sorológica, tendo em vista que o diagnóstico da toxoplasmose adquirida na gestação é eminentemente laboratorial.

A gestante que apresentar sororreatividade para toxoplasmose antes da gravidez indica infecção antiga, assim, para estas gestantes não há necessidade de realizar nova sorologia já que o risco de reinfecção é baixo. (DESMONTS; COUVREUR, 1974).

De acordo com os resultados encontrados na triagem sorológica realizada durante a primeira consulta pré-natal, são identificados quatro tipos de gestantes, descritos no item a seguir.

\section{Classificação dos casos de acordo com a sorologia - Algoritmos 1 e 2}

A) Gestante com infecção antiga, exposição anterior ao parasita (provavelmente imune).

- IgG reagente e lgM não reagente.

B) Gestante com possível infecção recente.

- $\lg G$ reagente e $\lg M$ reagente.

- Nesses casos, o laboratório deve realizar o teste de avidez de anticorpo lgG e/ou pesquisa de lgA, na mesma amostra de soro.

- A interpretação dependerá da idade gestacional no momento da coleta da amostra. 
C) Gestante possivelmente na fase inicial da infecção.

- IgG não reagente e $\lg M$ reagente.

- Deve ser confirmado com nova sorologia, em amostra coletada após 15 dias, para descartar resultado falso-positivo no teste de lgM.

D) Gestante suscetível ou de risco (não foi exposta ao T. gondii).

- $\lg G$ não reagente e $\lg M$ não reagente. 


\section{Algoritmo 1 | Interpretação de resultados e condutas para gestantes com até 16 semanas de gestação}

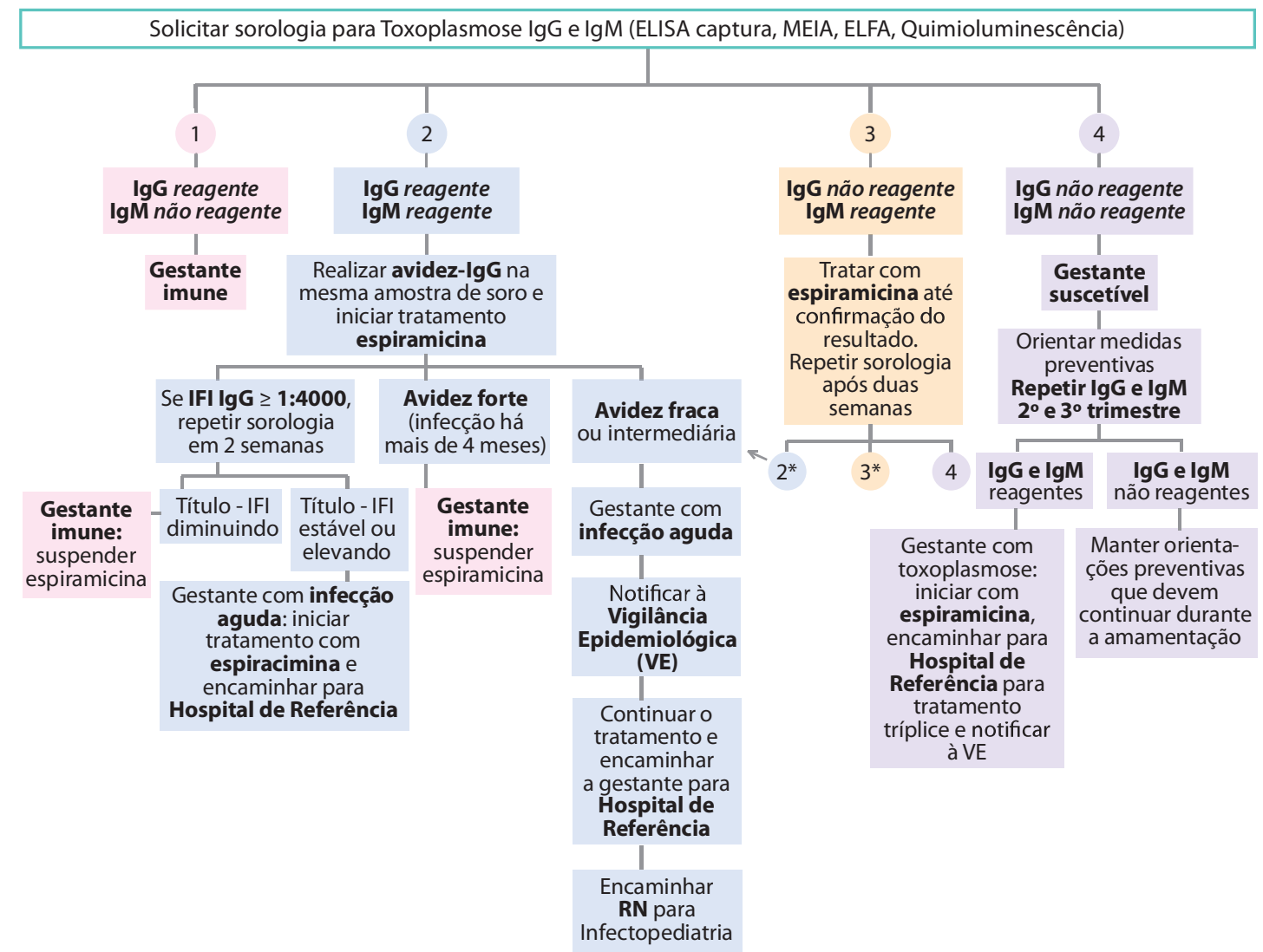

1 Se a gestante apresentar sintomatologia sugestiva ou ultrassonagrafia fetal com alteração: repetir sorologia.

2* Não há necessidade de fazer avidez-lgG, pois a soroconversão da lgG já confirma infecção recente.

$3^{*}$ Se mantiver resultado de lgG não reagente indica que lgM era falso reagente: considerar gestante suscetível. 


\section{Algoritmo 2 | Interpretação de resultados e condutas para gestantes a partir das $\mathbf{1 6}$ semanas de gestação}

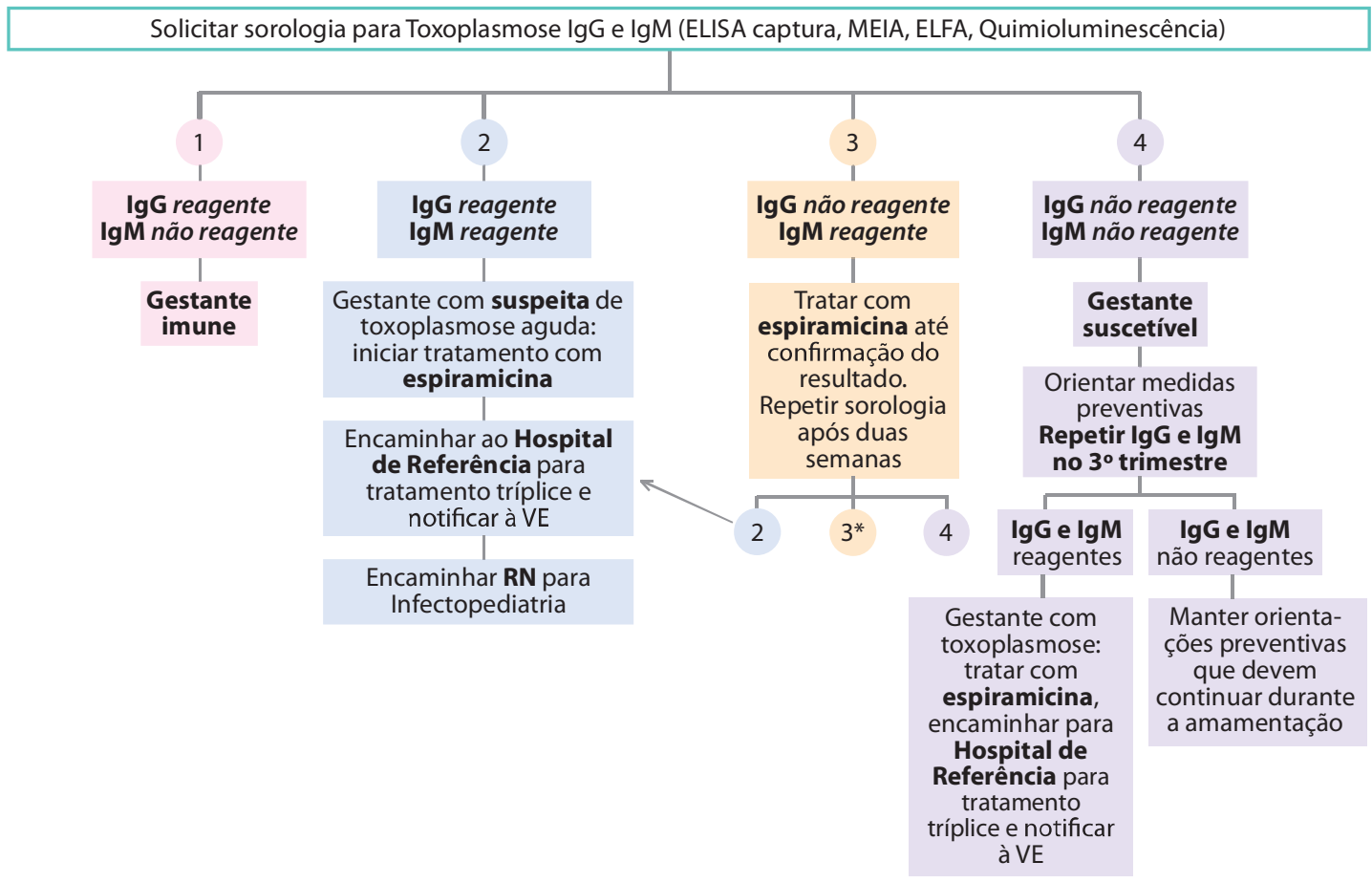

1 Se a gestante apresentar sintomatologia sugestiva ou ultrassonagrafia fetal com alteração: repetir sorologia.

3* Se mantiver resultado de lgG não reagente indica que lgM era falso reagente: considerar gestante suscetível. 


\section{Protocolos terapêuticos para a toxoplasmose materna}

Deve-se levar em consideração a idade gestacional e se a paciente está em investigação ou com infecção confirmada. (Quadros 6 e 7).

Recomenda-se o tratamento com o esquema tríplice para as gestantes com diagnóstico DEFINITIVO ou PROVÁVEL e tratamento com espiramicina para aquelas com diagnóstico POSSÍVEL, conforme a classificação de Lebech et al. (1996). (Quadro 4 na página 19).

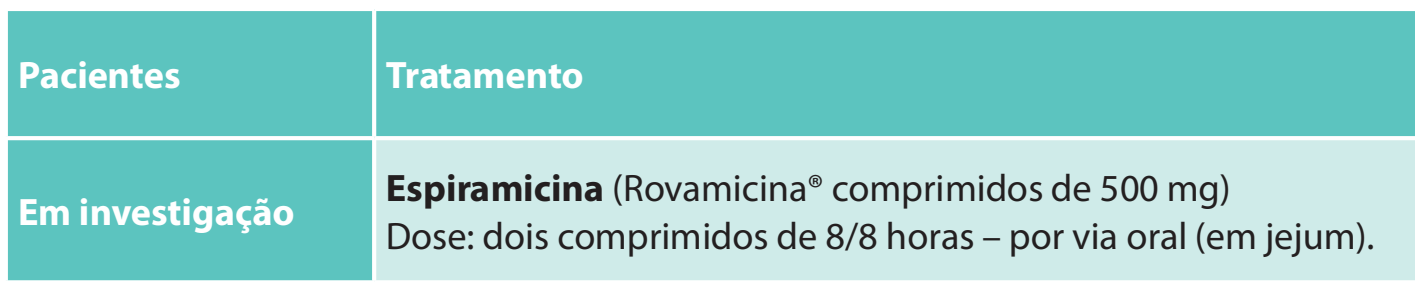

Quadro 6 - Esquema terapêutico para toxoplasmose adquirida na gestação para pacientes em investigação da infecção aguda, independentemente da idade gestacional. (REMINGTON et al., 2006). 


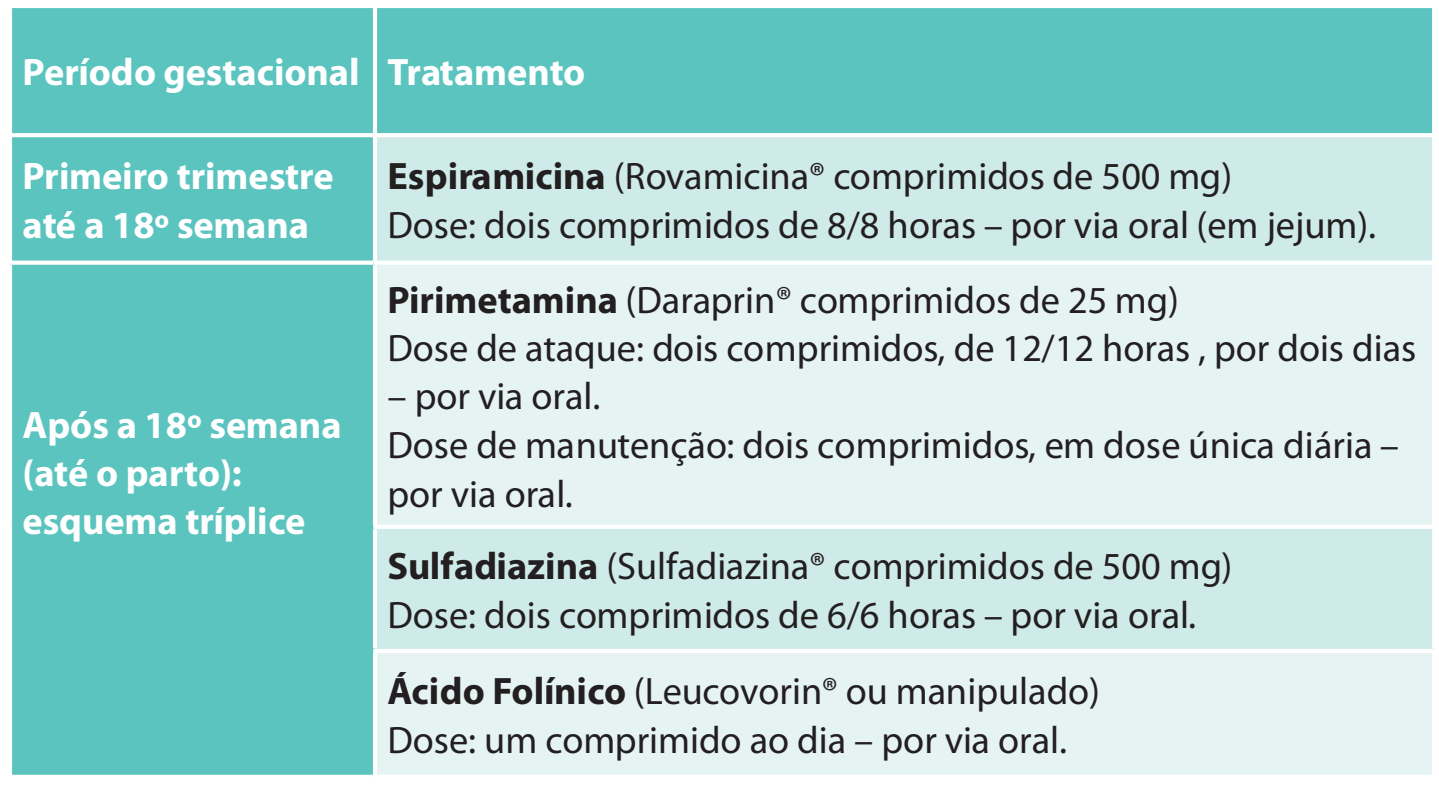

Quadro 7 - Esquema terapêutico para toxoplasmose adquirida na gestação para pacientes com infecção aguda. (REMINGTON et al., 2006).

Cuidados com o esquema tríplice:

- A pirimetamina é teratogênica e não pode ser usada durante o primeiro trimestre da gestação.

- O acido folínico é associado ao uso da pirimetamina, por ser esta um antagonista do ácido fólico. Deve ser administrado até uma semana após o uso da pirimetamina.

- Fazer controle hematológico mensal (hemograma e plaquetas), durante o uso da sulfadiazina e da pirimetamina, para diagnosticar alterações como anemia, plaquetopenia, leucopenia ou pancitopenia. Na presença dessas alterações, devese suspender por um mês o uso dos antimicrobianos e substituir por espiramicina, mantendo o ácido folínico.

- Na impossibilidade de uso de sulfadiazina e pirimetamina, deve-se fazer uso contínuo de espiramicina. 
- Em casos de intolerância ao tratamento, encaminhar a gestante à avaliação com médico infectologista para tratamento alternativo.

\section{Condutas}

\section{Gestantes com infecção antiga}

A) Avaliar a resposta imunológica. Investigar a presença de doenças ou tratamentos que acarretem imunodeficiência. Neste caso, fazem parte do grupo de risco as pacientes infectadas pelo HIV e gestantes que fazem uso de medicamentos imunossupressores (quimioterápicos e corticoides), ou portadoras de qualquer doença imunossupressora ou que utilizem outro medicamento que cause imunossupressão.

B) Se a criança nascer com sinais e sintomas sugestivos de toxoplasmose congênita, esta não deve ser descartada devido à possibilidade de reinfecção ou reagudização.

\section{Gestantes suscetíveis}

A) Instituir medidas de orientação para a prevenção primária da toxoplasmose por escrito e verbalmente (relembrar em todas as consultas).

B) Repetir sorologia no segundo e no terceiro trimestre para detectar a soroconversão.

Obs: Mulheres não devem engravidar até seis meses após soroconversão devido à possibilidade de parasitemia durante o período de, aproximadamente, três meses.

\section{Gestantes com infecção aguda}

A) Notificação obrigatória.

B) Instituir tratamento (Quadros 6 e 7):

- Primeiro trimestre até a $18^{a}$ semana de gestação: espiramicina.

- Segundo e terceiro trimestre a partir da 18a semana de gestação: esquema tríplice (sulfadiazina + pirimetamina + ácido folínico). 
C) Acompanhamento ultrassonográfico mensal.

D) Avaliação oftalmológica.

E) Anotar no cartão da gestante todos os resultados de exames laboratoriais, técnicas empregadas e valores de referência, medicamentos e esquema terapêutico utilizado, data e idade gestacional dos resultados de sorologias e do início do tratamento.

F) Se possível, encaminhar a gestante para realização de amniocentese para a detecção do DNA do parasita no líquido amniótico por PCR.

G) Realizar avaliação clínica e sorológica de todos os recém-nascidos de mães com toxoplasmose ativa ou suspeita.

Esses casos devem ser notificados para a Vigilância Epidemiológica local, onde será preenchida a ficha de investigação epidemiológica para toxoplasmose. Deve ser iniciado o tratamento e investigação da criança, conforme a rotina a seguir. 